\title{
Research into europium complexes as magnetic resonance imaging contrast agents (Review)
}

\author{
GUOCAN HAN ${ }^{1}$, YANGWEI DENG ${ }^{2}$, JIHONG SUN $^{1}$, JUN LING $^{2}$ and ZHIQUAN SHEN ${ }^{2}$ \\ ${ }^{1}$ Department of Radiology, Sir Run Run Shaw Hospital, School of Medicine, Zhejiang University, Hangzhou, \\ Zhejiang 310016; ${ }^{2}$ Ministry of Education Key Laboratory of Macromolecular Synthesis and Functionalization, \\ Department of Polymer Science and Engineering, Zhejiang University, Hangzhou, Zhejiang 310027, P.R. China
}

Received May 6, 2014; Accepted January 20, 2015

DOI: $10.3892 / \mathrm{etm} .2015 .2297$

\begin{abstract}
Europium (Eu) is a paramagnetic lanthanide element that possesses an outstanding luminescent property. Eu complexes are ideal fluorescence imaging (FI) agents. $\mathrm{Eu}^{2+}$ has satisfactory relaxivity and optical properties, and can realize magnetic resonance (MRI)-FI dual imaging applications when used with appropriate cryptands that render it oxidatively stable. By contrast, based on the chemical exchange saturation transfer (CEST) mechanism, $\mathrm{Eu}^{3+}$ complexes can provide enhanced MRI sensitivity when used with optimal cryptands, incorporated into polymeric CEST agents or blended with $\mathrm{Gd}^{3+}$. Eu complexes are promising in MRI-FI dual imaging applications and have a bright future.
\end{abstract}

\section{Contents}

1. Introduction

2. Studies of $\mathrm{Eu}^{2+}$ complexes as MRI contrast agents

3. MRI of $\mathrm{Eu}^{3+}$ complexes based on CEST

4. Conclusion and prospects

\section{Introduction}

Magnetic resonance imaging (MRI) is a useful medical imaging technique that utilizes the properties of nuclear magnetic resonance (NMR) to image the nuclei of atoms inside the body in detail and depth $(1,2)$. With high resolution and good safety, MRI is widely used as an efficient information source in medical diagnosis of the whole body. Fluorescence

Correspondence to: Dr Jun Ling, Ministry of Education Key Laboratory of Macromolecular Synthesis and Functionalization, Department of Polymer Science and Engineering, Zhejiang University, 38 Zheda Road, Hangzhou, Zhejiang 310027, P.R. China E-mail: junlingcn@126.com

Key words: europium, magnetic resonance imaging, cryptand, longitudinal relaxivity, transverse relaxivity imaging (FI) provides better sensitivity than MRI, but cannot show tissues at different levels. The combination of MRI and FI, as a dual imaging application, should provide a balance between iconography and histology. In addition, diagnosis and treatment are likely to be more accurate and sensitive with an approach where tumors are positioned with MRI and completely removed under the guidance of FI.

The ability of contrast agents to alter the relaxivity of the protons of water molecules that are coordinated to tissue is the key of MRI (1). The trivalent gadolinium ion $\left(\mathrm{Gd}^{3+}\right)$ has seven unpaired electrons in its outer electron shell, which makes it highly paramagnetic with a short spin-lattice relaxation time (longitudinal relaxation time, T1), and complexes of $\mathrm{Gd}^{3+}$ have been widely used as MRI contrast agents (3). $\mathrm{Gd}^{3+}$ has a similar size to $\mathrm{Ca}^{2+}$ and so the former tends to interfere in the metabolism of $\mathrm{Ca}^{2+}$ in the human body. Therefore, ligands are necessary to reduce the toxicity. Functional groups on the ligands can also be designed to bond with nanoparticles (NPs), in order to extend the rotational correlation time and enhance relaxivity. Ligands that are frequently used include diethylene triamine pentacetic acid (DTPA), 1,4,7,10-tetraazacyclododecane-1,4,7,10-tetraacetic acid (DOTA) and their derivatives (Fig. 1) $(3,4)$.

Europium (Eu) is also lanthanide element, which is adjacent to gadolinium in the periodic table, and the application of its ions in MRI has also been the object of attention. $\mathrm{Eu}^{3+}$ has six unpaired electrons in the outer electron shell, which is indicative of good paramagnetism. It is photoluminescent, can emit strong fluorescence $(585-630 \mathrm{~nm}$, red) with a long life-time and is barely toxic. If the MRI and FI functions of complexed $\mathrm{Eu}$ are both achieved, and the complexes possess sensitivity and accuracy, a series of promising applications are predicted. $\mathrm{Xu}$ et al presented a variety of lanthanide oxide $\left(\mathrm{Ln}_{2} \mathrm{O}_{3}\right)$ NPs and studied their water proton relaxivities (5). The authors coated $\mathrm{Ln}_{2} \mathrm{O}_{3}$ with D-glucuronic acid to prepare ultrasmall NPs (with diameters of $\sim 2 \mathrm{~nm}$ ), and measured their longitudinal relaxivity (r1) and transverse relaxivity (spin-spin relaxivity; r2). The results are listed in Table I (6), and show that the D-glucuronic acid-coated ultrasmall $\mathrm{Eu}_{2} \mathrm{O}_{3}$ NPs are not outstanding in $\mathrm{r} 1$ or $\mathrm{r} 2$. This may be attributed to the spin relaxation time of $\mathrm{Eu}^{3+}$ being too short to alter the relaxivity of protons. To achieve MRI-FI dual imaging, the optimal method is to blend Eu 

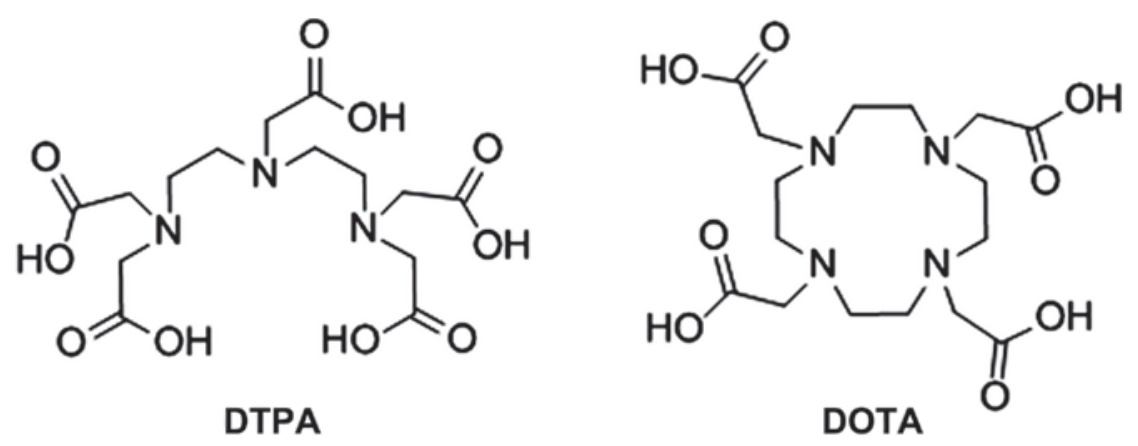

Figure 1. Frequently used ligands, diethylene triamine pentacetic acid (DTPA) and 1,4,7,10-tetraazacyclododecane-1,4,7,10-tetraacetic acid (DOTA).

complexes with routine MRI contrast agents, for example, $\mathrm{Gd}^{3+}$ complexes $(5,7)$ and $\mathrm{Fe}_{3} \mathrm{O}_{4}(8,9)$. Pinho et al studied the dual imaging capabilities of lanthanide-DTPA-grafted silica NPs, in which $\mathrm{Eu}^{3+}$ and $\mathrm{Gd}^{3+}$ complexes were blended together $\left[\mathrm{SiO}_{2} @ 3\right.$-aminopropyl-triethoxysilane (APS)/DTPA:Gd:Eu] (7). The results revealed that the existence of $\mathrm{Gd}^{3+}$ did not disturb the photoluminescence of $\mathrm{Eu}^{3+}$, while the addition of $\mathrm{Eu}^{3+}$ enhanced the relaxivity of $\mathrm{Gd}^{3+}$.

However, in order to realize MRI-FI dual imaging with Eu complexes in the absence of highly paramagnetic ions, it is necessary to focus attention on improving the MRI properties of Eu complexes.

\section{Studies of $\mathrm{Eu}^{2+}$ complexes as MRI contrast agents}

$\mathrm{Eu}^{2+}$ has seven unpaired electrons in its outer electron shell, as does $\mathrm{Gd}^{3+}$. However, $\mathrm{Eu}^{2+}$ has a larger ion size than $\mathrm{Gd}^{3+}$ and a lower charge, which gives $\mathrm{Eu}^{2+}$ a faster water-exchange rate and guarantees a relatively high relaxivity (10). $\mathrm{Eu}^{2+}$ is also photoluminescent; $\mathrm{f} \rightarrow \mathrm{d}$ transitions have been observed in $\mathrm{Eu}^{2+}$, which have longer radiative emission lifetimes than $\mathrm{f} \rightarrow \mathrm{f}$ transitions in $\mathrm{Eu}^{3+}(11)$. However, the relaxivity of $\mathrm{Eu}^{2+}$-containing DTPA chelates has been found to be $20 \%$ lower than that of $\mathrm{Gd}^{3+}$-DTPA complexes at $20 \mathrm{MHz}$, which may be attributed to the fast ionic spin relaxation of $\mathrm{Eu}^{2+}(12)$. Not all $\mathrm{Eu}^{2+}$ complexes are restricted by ionic spin relaxation. The relaxivity of $\mathrm{Eu}^{2+}$-DOTA complexes has been shown to reach $4.74 \mathrm{mM}^{-1} \mathrm{sec}^{-1}$ at $20 \mathrm{MHz}$ and $298 \mathrm{~K}$, much higher than that of $\mathrm{Eu}^{2+}$-DTPA complexes (13). A fast water-exchange rate of $\mathrm{Eu}^{2+}$ is able to offset the disadvantage in ionic spin relaxation time.

The biggest obstacle in the development of MRI applications of $\mathrm{Eu}^{2+}$ complexes is the oxidative stability of the ion. $\mathrm{Eu}^{2+}$ has a propensity for being oxidized to $\mathrm{Eu}^{3+}$, which possesses low relaxivity and relatively high toxicity. Coordination chemistry principles can be used to oxidatively stabilize $\mathrm{Eu}^{2+}$ without weakening the relaxivity and water-exchange rate. 4,7,13,16,21,24-Hexaoxa-1,10-diazabicyclo[8.8.8]hexacosane (crypt-222; ligand 1 in Fig. 2A) is known to have an appropriate cage size for $\mathrm{Eu}^{2+}$, and the crypt-222 complex $\left[\mathrm{Eu} \text { (crypt-222) }\left(\mathrm{H}_{2} \mathrm{O}\right)_{2}\right]^{2+}$ is one of the most redox-stable $\mathrm{Eu}^{2+}$ chelates (14). [Eu(crypt-222) $]^{2+}$ coordinates immediately with two water molecules, and possesses an appropriate water-exchange rate and ionic spin relaxation time. However, $\left[\mathrm{Eu}(\mathrm{crypt}-222)\left(\mathrm{H}_{2} \mathrm{O}\right)_{2}\right]^{2+}$ is not sufficiently stable for the development of MRI applications in aqueous solution. However, it is potentially useful as a $\mathrm{pO}_{2}$-responsive macromolecular MRI contrast agent (14).

To obtain oxidatively stable aqueous $\mathrm{Eu}^{2+}$ complexes, Gamage et al carried out research and development based on the coordination of crypt-222 (15). The goals were: i) to increase the surrounding steric bulk to minimize interactions between $\mathrm{Eu}^{2+}$ and its environment; ii) to reduce the Lewis basicity of crypt-222 to favor $\mathrm{Eu}^{2+}$ over $\mathrm{Eu}^{3+}$; iii) to change the cavity size of the cryptand to match the size of the $\mathrm{Eu}^{2+}$ ion preferentially; and iv) to modify the hard-soft, acid-base (HSAB) properties of crypt-222 to coordinate $\mathrm{Eu}^{2+}$ in preference to $\mathrm{Eu}^{3+}$. The authors presented five ligands (ligands 2-6 in Fig. 2) with crypt-222 as the prototype.

The steric bulk of ligand 2 was increased by the addition of methyl groups. Benzene rings were introduced to decrease the ion-donating ability of the adjacent oxygen atoms of ligands 3-5. The introduction of fluorine in ligand 4 and another benzene ring in ligand 5 modulated the extent of ion withdrawal. The existence of fused benzene moieties decreased the cavity size of the cryptand and provided a cavity size closer to that of $\mathrm{Eu}^{2+}$. In ligand 6, relatively soft sulfur-atom donors were introduced to take the place of oxygen-atom donors, enabling the influence of HSAB properties to be explored. In situ, the authors mixed these ligands with $\mathrm{Eu}\left(\mathrm{NO}_{3}\right)_{3} \cdot 5 \mathrm{H}_{2} \mathrm{O}$ in aqueous solution. The mixture was placed in a standard three-electrode cell while the potential at the carbon electrode was held at $-0.8 \mathrm{~V}$ to achieve metal complexation. Cyclic voltammograms were obtained following metallation for each complex in solution with ferrocene as an internal standard. Anodic peak potentials for each complex were obtained and are listed in Table II.

The results revealed that the new ligands all increased the oxidative stability of $\mathrm{Eu}^{2+}$ to a certain degree. There was almost no difference between the Eu complexes of ligands 5 and 3 , indicating that the addition of one benzene ring was sufficient for stabilization. The Eu complex of ligand 6 had the highest anodic peak potential, higher than that of $\mathrm{Fe}^{2+}$-hemoglobin, suggesting that it was an efficient ligand to prevent $\mathrm{Eu}^{2+}$ from oxidation. Garcia et al also reported the stability of Eu complexes with ligands 1 and 3 in the presence of $\mathrm{Ca}^{2+}, \mathrm{Mg}^{2+}$ and $\mathrm{Zn}^{2+}(16)$, and the study indicated that the $\mathrm{Eu}^{2+}$ complexes remained stable in the presence of $\mathrm{Ca}^{2+}$, $\mathrm{Mg}^{2+}$ and $\mathrm{Zn}^{2+}$ at concentrations 1.87-20-fold higher than biological concentrations. $\mathrm{Eu}^{2+}$ complexes have the potential to realize durable biological oxidative stability, and provide satisfactory magnetic and spectroscopic properties in vivo. 
Table I. Average particle diameter $\left(\mathrm{d}_{\text {avg }}\right)$, r1 , and $\mathrm{r} 2$ of D-glucuronic acid-coated ultrasmall $\mathrm{Ln}_{2} \mathrm{O}_{3}$ nanoparticles and the $\mathrm{M}$ values of $\mathrm{Ln}(\mathrm{III})$ in ultrasmall $\mathrm{Ln}_{2} \mathrm{O}_{3}$ nanoparticles (6).

\begin{tabular}{|c|c|c|c|c|c|}
\hline \multirow{2}{*}{$\begin{array}{l}\mathrm{Ln}_{2} \mathrm{O}_{3} \\
\text { nanoparticle }\end{array}$} & \multirow[b]{2}{*}{$\mathrm{d}_{\mathrm{avg}}(\mathrm{nm})$} & \multicolumn{2}{|c|}{$\mathrm{M}^{\mathrm{a}}\left(\mu_{\mathrm{B}}\right)$} & \multirow[b]{2}{*}{$\mathrm{r} 1^{\mathrm{b}}\left(\mathrm{mM}^{-1} \sec ^{-1}\right)$} & \multirow[b]{2}{*}{$\mathrm{r} 2^{\mathrm{b}}\left(\mathrm{mM}^{-1} \mathrm{sec}^{-1}\right)$} \\
\hline & & $5 \mathrm{~K}$ & $300 \mathrm{~K}$ & & \\
\hline $\mathrm{Eu}_{2} \mathrm{O}_{3}$ & 2.0 & 0.078 & 0.046 & 0.006 & 3.82 \\
\hline $\mathrm{Gd}_{2} \mathrm{O}_{3}$ & 2.4 & 6.42 & 0.24 & 4.25 & 27.11 \\
\hline $\mathrm{Dy}_{2} \mathrm{O}_{3}$ & 2.9 & 5.19 & 0.42 & 0.16 & 40.28 \\
\hline $\mathrm{Ho}_{2} \mathrm{O}_{3}$ & 2.4 & 4.66 & 0.39 & 0.13 & 31.24 \\
\hline $\mathrm{Er}_{2} \mathrm{O}_{3}$ & 2.9 & 4.52 & 0.34 & 0.06 & 14.74 \\
\hline
\end{tabular}

${ }^{\mathrm{a}}$ Measured with a magnetic field intensity of $5 \mathrm{~T}$. ${ }^{\mathrm{b}} \mathrm{Measured}$ at $22^{\circ} \mathrm{C}$ with a magnetic field intensity of $1.5 \mathrm{~T}$. r1, longitudinal relaxivity; r2, transverse relaxivity; Ln, lanthanide; Eu, europium, Gd, gadolinium; Dy, dysprosium; Ho, holmium; Er, erbium; M, magnetization.

Table II. Anodic peak potentials (Epa) of various samples with respect to ferrocene/ferrocenium $\left(\mathrm{Fc} / \mathrm{Fc}^{+}\right)$.

\begin{tabular}{lclr}
\hline Sample & Epa vs. Fc/Fc $(\mathrm{V})$ & Sample & Epa vs. Fc/Fc $(\mathrm{V})$ \\
\hline $1 . \mathrm{Eu}\left(\mathrm{NO}_{3}\right)_{3}$ & $-0.701 \pm 0.030$ & 5. Eu-2 & $-0.169 \pm 0.006$ \\
2. Eu-1 & $-0.336 \pm 0.016$ & 6. Eu-4 & $-0.079 \pm 0.007$ \\
3. Eu-5 & $-0.211 \pm 0.004$ & 7. hemoglobin & $-0.070 \pm 0.003$ \\
4. Eu-3 & $-0.208 \pm 0.009$ & 8. Eu-6 & $-0.035 \pm 0.010$
\end{tabular}

Eu-n $(n=1-6)$ is a complex of europium $\left(\mathrm{Eu}^{2+}\right)$ with ligand $n$; ligand 1 is 4,7,13,16,21,24-hexaoxa-1,10-diazabicyclo[8.8.8]hexacosane (crypt-222); ligands 2-6 are crypt-222 derivatives as shown in Fig. 2.<smiles>C1COCCOCCN2CCOCCN(CCOCCOCCO1)CC2</smiles>

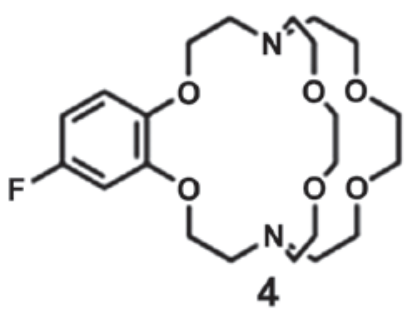

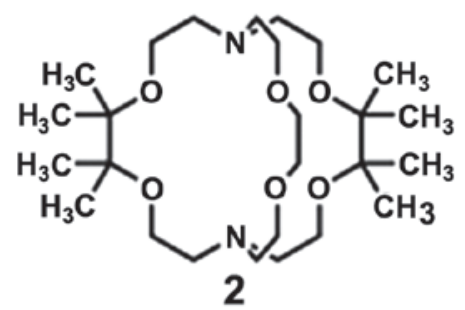

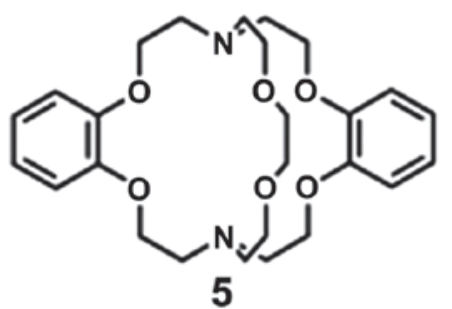<smiles>OCCOCCOCCOCCOCCN1CCOc2ccccc2OCC1</smiles>

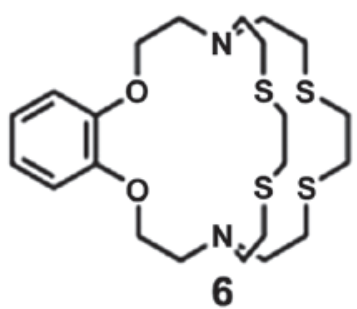

Figure 2. 4,7,13,16,21,24-Hexaoxa-1,10-diazabicyclo[8.8.8]hexacosane (crypt-222; ligand 1) and its derivatives (ligands 2-6).

\section{MRI of $\mathrm{Eu}^{3+}$ complexes based on CEST}

Chemical exchange saturation transfer (CEST) is a novel mechanism for generating image contrast in MRI (1). Protons on ligands or water molecules coordinated with a metal ion are saturated by a radiofrequency pulse and then exchanged with bulk water molecules, presenting a negative image. Imaging can be made more efficient by the utilization of paramagnetic nuclei. The effects of these agents, referred to as PARACEST agents, can be switched on and off depending on the application of radiofrequency radiation. Theoretically, with an optimal water-exchange rate, chemical shift and relaxation properties, the detection limit of a single PARACEST exchanging species is comparable to that of a single $\mathrm{Gd}^{3+}$-based $\mathrm{T} 1$ imaging agent (17). The applications of CEST include the visualization of living tissue structure, the imaging of metabolic processes, the marking of cells and $\mathrm{pH}$ measurements (18). 
<smiles>CCOC(=O)CNC(=O)CN1CCN(CC(=O)NCC(=O)OCC)CCN(CC(=O)OCC)N(CC(=O)NCC(=O)OCC)CC1</smiles>

Figure 3. 1,4,7,10-Tetraazacyclododecane tetrakis (ethyl-acetamidoacetate), ligand 7. Et, ethyl.

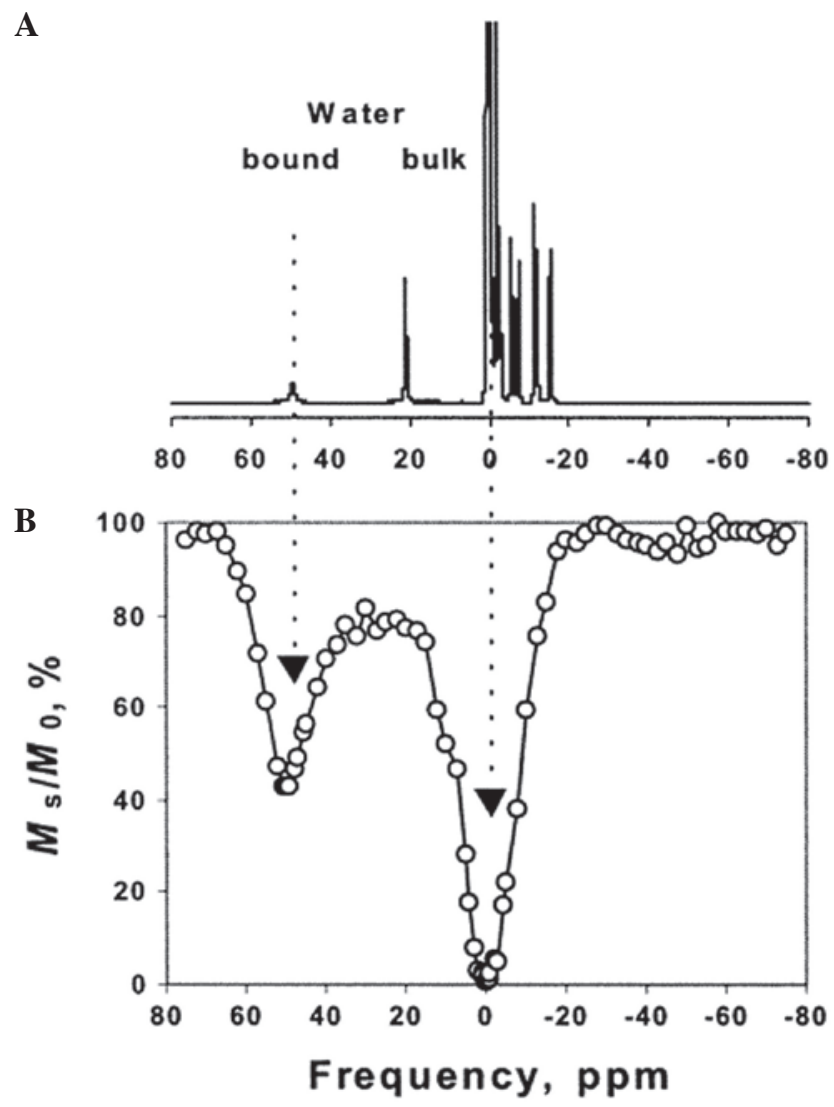

Figure 4. (A) ${ }^{1} \mathrm{H}$ nuclear magnetic resonance spectrum and (B) chemical exchange saturation transfer curve of Eu-7 in aqueous solution. Eu-7 is a complex of europium $\left(\mathrm{Eu}^{3+}\right)$ with 1,4,7,10-tetraazacyclododecane tetrakis(ethyl-acetamidoacetate). $\mathrm{M}_{\mathrm{s}} / \mathrm{M}_{0}$, ratio of saturated protons; $\mathrm{M}_{\mathrm{s}, \text { water }}$ proton signal in the presence of saturation; $\mathrm{M}_{0}$, signal under control conditions; ppm, parts per million.

Zhang et al studied the CEST properties of a complex of $\mathrm{Eu}^{3+}$ with a DOTA-tetraamide derivative (ligand 7 in Fig. 3) (19). ${ }^{1} \mathrm{H}$ NMR spectroscopy was used to examine an aqueous solution of the Eu complex of ligand 7 (Fig. 4A). The peak corresponding to complexed water shifted to $\sim 50 \mathrm{ppm}$. If protons were exchanged between the complexed water and bulk water following the application of radiofrequency energy, the signal intensities of would change, revealing directly the ratio of saturated protons. The ratio of saturated protons is defined as $M_{s} / M_{0}$, where $M_{s}$ is the water proton signal in the presence of saturation and $\mathrm{M}_{0}$ is the signal under control conditions. CEST curves were drawn based on the aforementioned
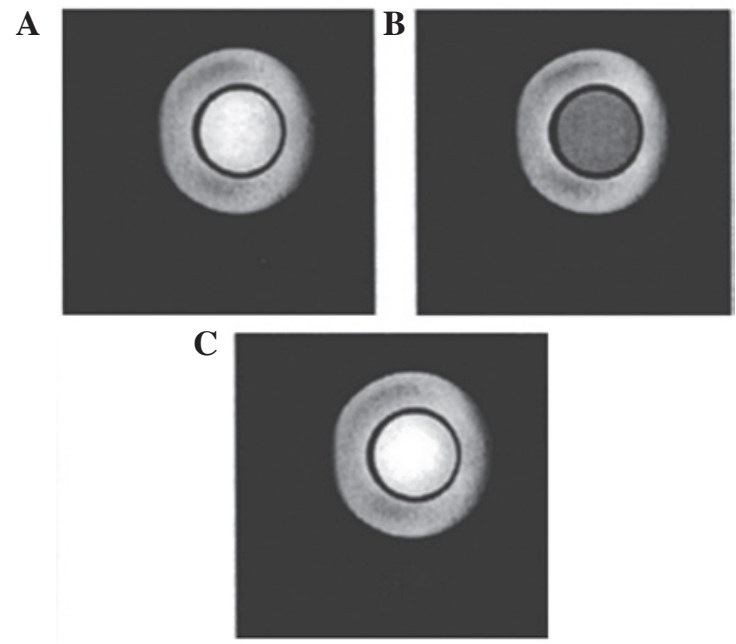

Figure 5. Magnetization transfer T1-weighted spin-echo images of a phantom. The outer vial contained deionized water, while inner vial contained $63 \mathrm{mM}$ Eu-7 dissolved in pure water. (A) No saturation, (B) saturation at $+9,800 \mathrm{~Hz}$ and $(\mathrm{C})$ saturation at $-9,800 \mathrm{~Hz}$. Eu-7 is a complex of europium $\left(\mathrm{Eu}^{3+}\right)$ with 1,4,7,10-tetraazacyclododecane tetrakis(ethyl-acetamidoacetate).

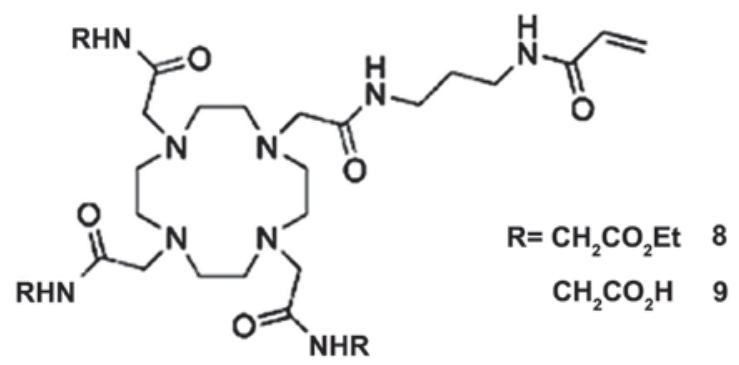

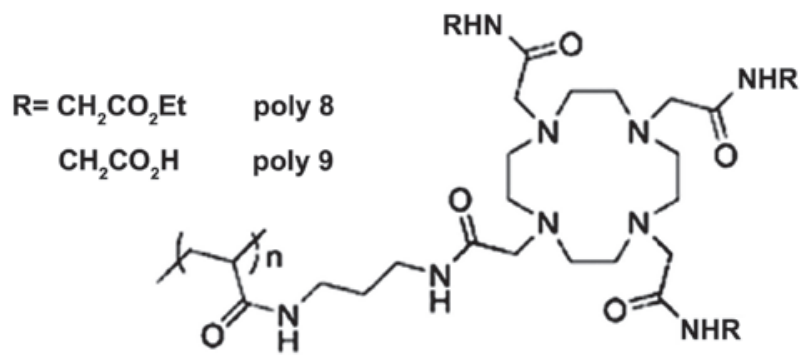

Figure 6. 1,4,7,10-Tetraazacyclododecane-1,4,7,10-tetraacetic acid derivatives with acrylamide substituents (ligands 8 and 9) and their polymers (poly 8 and poly 9 , respectively). Et, ethyl.

method (Fig. 4B). Lower $\mathrm{M}_{\mathrm{s}} \mathrm{M}_{0}$ values indicated higher CEST effects. Magnetization transfer T1-weighted spin-echo images for a phantom were obtained with no saturation (Fig. 5A), saturation at $+9,800 \mathrm{~Hz}$ (Fig. 5B) and saturation at $-9,800 \mathrm{~Hz}$ (Fig. 5C). The image at $+9,800 \mathrm{~Hz}$ was dimmer than the others, demonstrating the weakening effect of CEST on the magnetic resonance signals of protons, and the ability to be switched on and off at will was achieved.

To lower the detection limit of PARACEST agents, Wu et al reported the polymerization of PARACEST agents in order to enhance MRI contrast sensitivity (17). The authors presented two kinds of DOTA ligands with acrylamide substituents to coordinate with $\mathrm{Eu}^{3+}$ (ligands 8 and 9 in Fig. 6), and synthesized 


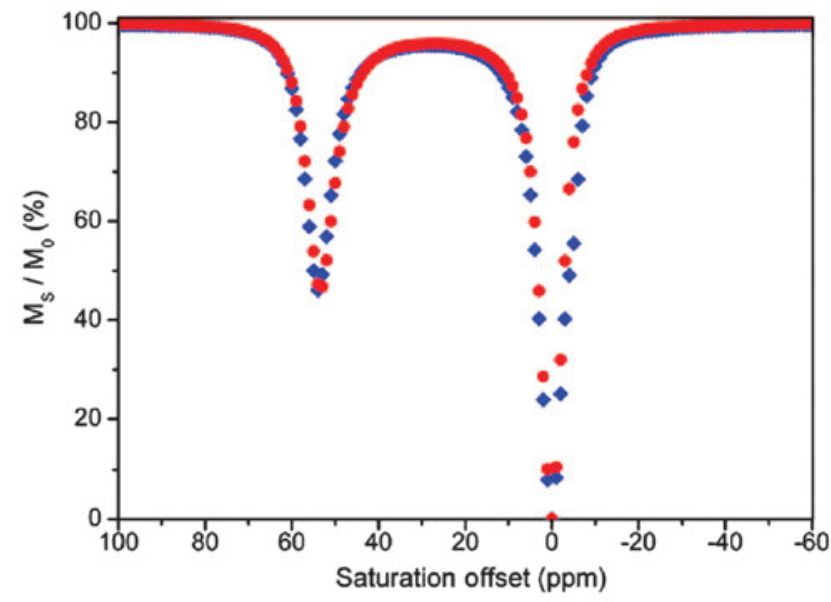

Figure 7. Chemical exchange saturation transfer spectra of Eu-9 (red) and Eu-poly 9 (2\%; blue); concentration of Eu ${ }^{3+}, 30 \mathrm{mM}$. Eu-9 is a complex of europium $\left(\mathrm{Eu}^{3+}\right)$ with an acrylamide-substituted derivative of 1,4,7,10-tetraazacyclododecane-1,4,7,10-tetraacetic acid (ligand 9), and Eu-poly 9 is a complex of $\mathrm{Eu}^{3+}$ with a polymer of ligand $9 . \mathrm{M}_{\mathrm{s}} / \mathrm{M}_{0}$, ratio of saturated protons; $M_{s}$ water proton signal in the presence of saturation; $M_{0}$, signal under control conditions; ppm, parts per million.

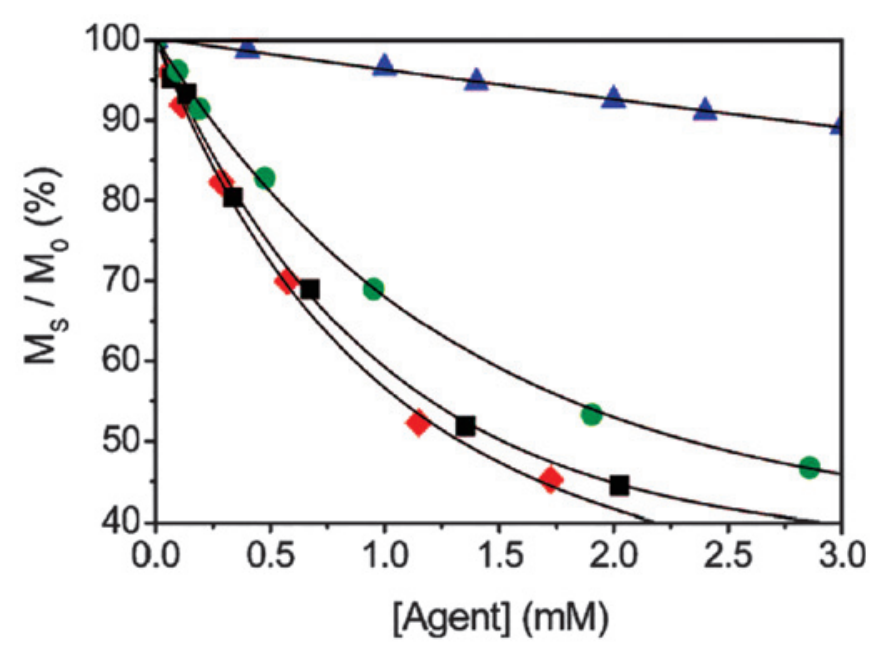

Figure 8. Maximum chemical exchange saturation transfer per concentration of agent [agent] for Eu-9 $(\mathbf{\Delta})$ and Eu-poly $9(\bullet, 2 \% ; \cdot, 5 \%$; $\$ 10 \%)$. Eu-9 is a complex of europium $\left(\mathrm{Eu}^{3+}\right)$ with an acrylamide-substituted derivative of 1,4,7,10-tetraazacyclododecane-1,4,7,10-tetraacetic acid (ligand 9), and Eu-poly 9 is a complex of $\mathrm{Eu}^{3+}$ with a polymer of ligand $9 . \mathrm{M}_{\mathrm{s}} / \mathrm{M}_{0}$, ratio of saturated protons; $\mathrm{M}_{\mathrm{s},}$ water proton signal in the presence of saturation; $\mathrm{M}_{0}$, signal under control conditions.

polymeric ligands by the respective radical polymerization of ligands 8 and 9 (poly 8 and poly 9 in Fig. 6). The CEST spectra of Eu complexes of ligands 9 and poly 9 were almost identical at equal $\mathrm{Eu}^{3+}$ concentrations (Fig. 7), suggesting that the polymerization had no impact of the exchange of protons. A comparison among the maximum CEST for each concentration of the Eu complexes of ligand 9 and poly 9 with different initiator ratios (Fig. 8) revealed that polymerization efficiently lowered the detection limit.

In another article from these authors, 2-methylacrylic acid (MAA), 2-(acryloylamino)-2-methyl-1-propanesulfonic acid (AMPS) and N-isopropylacrylamide (NIPAM) were respectively used to copolymerize with ligand 9 , to form the polymers

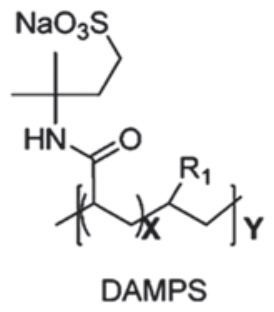<smiles>[Y]CC([R])(CC(C)(C)C(=O)NC(C)C)C(=O)NC(C)C</smiles><smiles>[R]COC(=O)CN1CCN(CC(=O)N[R])CCN(CC(=O)NCCCNC(C)=O)CCN(CC(=O)N[R])CC1</smiles>

Figure 9. Copolymers of an acrylamide-substituted derivative of 1,4,7,10-tetraazacyclododecane-1,4,7,10-tetraacetic acid (ligand 9) with 2-methylacrylic acid (MAA), 2-(acryloylamino)-2-methyl-1-propanesulfonic acid (AMPS) and N-isopropylacrylamide (NIPAM). Et, ethyl; D, ligand 9.

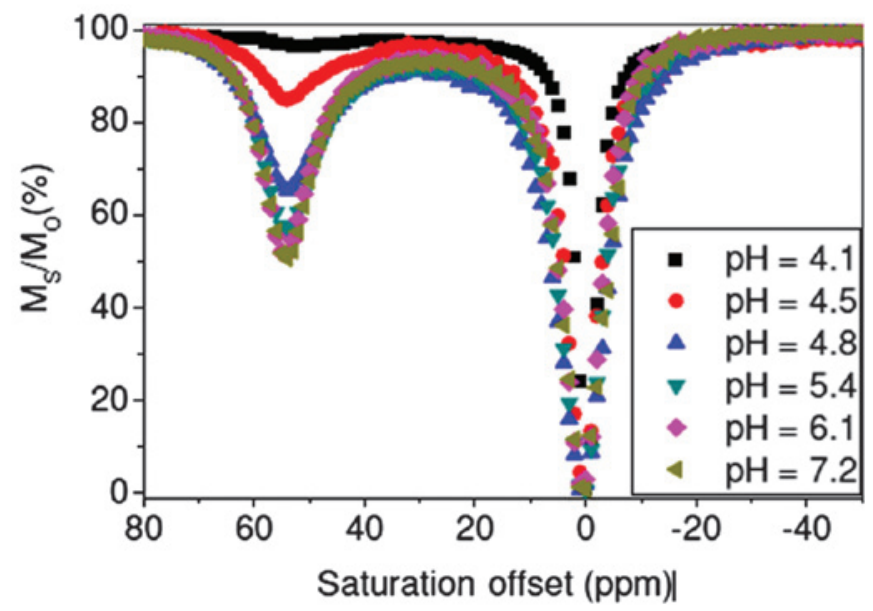

Figure 10. Chemical exchange saturation transfer curves of Eu-DMAA at different $\mathrm{pH}$ values. Eu-DMAA is a complex of europium $\left(\mathrm{Eu}^{3+}\right)$ with a copolymer of an acrylamide-substituted derivative of 1,4,7,10-tetraazacyclododecane-1,4,7,10-tetraacetic acid (ligand 9) and 2-methylacrylic acid (MAA). $\mathrm{M}_{\mathrm{s}} / \mathrm{M}_{0}$, ratio of saturated protons; $\mathrm{M}_{\mathrm{s}}$, water proton signal in the presence of saturation; $\mathrm{M}_{0}$, signal under control conditions; ppm, parts per million.

DMAA, DAMPS and DNIPAM (D: ligand 9), respectively (Fig. 9), in order to investigate the effect of water-exchange rate on the CEST properties of $\mathrm{Eu}^{3+}$ complexes (20).

Unlike $\mathrm{Gd}^{3+}$-based $\mathrm{T} 1$ imaging agents that rely on rapid water exchange between metal ion-bound water and bulk solvent, the signals of PARACEST agents become quenched as the bound protons on the agent are not readily saturated at a rapid water-exchange rate; they require moderate-to-slow water exchange rates for optimal performance. From the CEST results of an Eu complex of DMAA at different $\mathrm{pH}$ values (Fig. 10), the signals were attenuated as the $\mathrm{pH}$ was reduced from 8 to 4 . The carboxyl group was stable enough to bond with water at lower $\mathrm{pH}$ and water exchange between water and the complexes was promoted. Copolymerization also rendered the 
complexes responsive to temperature. The water-exchange rate increased as the temperature rose. However, unlike DMAA, which is hydrophilic along the full length of the polymer, the interaction between water and the side groups of DNIPAM was attenuated when the temperature rose, and the side groups tended to aggregate against water, which avoided an unfavorably rapid exchange rate. The aforementioned factors explain why changes in the signals generated by the Eu-DNIPAM complex were more moderate than those generated by Eu-DMAA as the temperature changed. The results of these studies indicate that $\mathrm{Eu}^{3+}$-based CEST agents are promising for use in $\mathrm{pH}$ - and temperature-responsive MRI applications.

\section{Conclusion and prospects}

$\mathrm{Eu}^{3+}$ and $\mathrm{Eu}^{2+}$ possesses six and seven unpaired electrons in the 4f orbital, respectively, which is indicative of paramagnetism. However, the short ionic spin relaxation time of $\mathrm{Eu}^{3+}$ and the propensity of $\mathrm{Eu}^{2+}$ to be oxidized result in the MRI properties of Eu complexes being inferior to those of Gd complexes. The design of ligands and enhancement by CEST are the main approaches at present to compensate for the deficiencies of $\mathrm{Eu}$ ions, enhance their properties as MRI contrast agents and eventually realize MRI-FI dual imaging with further efforts.

\section{Acknowledgements}

This study was supported by National Basic Research Program of China (973 Program, no. 2014CB744505), National Natural Science Foundation of China (no. 81430040) and Scientific Research Foundation of Health Bureau of Zhejiang Province in China (no. 2014PYA010).

\section{References}

1. Dorweiler JD, Nemykin VN, Ley AN, Pike RD and Berry SM: Structural and NMR characterization of Sm(III), Eu(III) and $\mathrm{Yb}$ (III) complexes of an amide based polydentate ligand exhibiting paramagnetic chemical exchange saturation transfer abilities. Inorg Chem 48: 9365-9376, 2009.

2. Wang LY, Chen QY and Wei B: MRI contrast agent for the diagnosis of tumor. Hua Xue Jin Zhan 22: 186-193, 2010 (In Chinese).

3. Liu Y and Zhang N: Gadolinium loaded nanoparticles in theranostic magnetic resonance imaging. Biomaterials 33: 5363-5375, 2012.

4. Lee GH, Chang YM and Kim TJ: Blood-pool and targeting MRI contrast agents: From Gd-chelates to Gd-nanoparticles. Eur J Inorg Chem 2012: 1924-1933, 2012.
5. Xu W, Kattel K, Park JY, Chang Y, Kim TJ and Lee GH: Paramagnetic nanoparticle T1 and T2 MRI contrast agents. Phys Chem Chem Phys 14: 12687-12700, 2012.

6. Kattel K, Park JY, Xu W, et al: A facile synthesis, in vitro and in vivo MR studies of D-glucuronic acid-coated ultrasmall $\mathrm{Ln}_{2} \mathrm{O}_{3}$ $(\mathrm{Ln}=\mathrm{Eu}, \mathrm{Gd}, \mathrm{Dy}, \mathrm{Ho}$ and $\mathrm{Er}$ ) nanoparticles as a new potential MRI contrast agent. ACS Appl Mater Interfaces 3: 3325-3334, 2011.

7. Pinho SL, Faneca H, Geraldes CF, Delville MH, Carlos LD and Rocha J: Lanthanide-DTPA grafted silica nanoparticles as bimodal-imaging contrast agents. Biomaterials 33: 925-935, 2012.

8. Wang W, Zou M and Chen K: Novel $\mathrm{Fe}_{3} \mathrm{O}_{4} @ \mathrm{YPO}_{4}: \mathrm{Re}(\mathrm{Re}=\mathrm{Tb}$, $\mathrm{Eu})$ multifunctional magnetic-fluorescent hybrid spheres for biomedical applications. Chem Commun (Camb) 46: 5100-5102, 2010.

9. Xi P, Cheng K, Sun X, Zeng Z and Sun S: Magnetic $\mathrm{Fe}_{3} \mathrm{O}_{4}$ nanoparticles coupled with a fluorescent Eu complex for dual imaging applications. Chem Commun (Camb) 48: 2952-2954, 2012 .

10. Garcia $\mathrm{J}$ and Allen MJ: Developments in the coordination chemistry of europium (II). Eur J Inorg Chem 2012: 4550-4563, 2012.

11. Kim JM, Jeong YK, Sohn Y and Kang JG: Synthesis and photophysical properties of an Eu(II)-complex/PS blend: Role of Ag nanoparticles in surface-enhanced luminescence. Langmuir 28: 9842-9848, 2012.

12. Seibig S, Tóth É and Merbach AE: Unexpected differences in the dynamics and in the nuclear and electronic relaxation properties of the isoelectronic $\left[\mathrm{Eu}^{\mathrm{II}}(\mathrm{DTPA})\left(\mathrm{H}_{2} \mathrm{O}\right)\right]^{3-}$ and $\left[\mathrm{Gd}^{\mathrm{III}}(\mathrm{DTPA})\right.$ $\left.\left(\mathrm{H}_{2} \mathrm{O}\right)\right]^{2-}$ complexes $($ DTPA $=$ diethylenetriaminepentaacetate $)$. J Am Chem Soc 122: 5822-5830, 2000.

13. Burai L, Tóth É, Moreau G, Sour A, Scopelliti R and Merbach AE: Novel macrocyclic Eu ${ }^{\mathrm{II}}$ complexes: Fast water exchange related to an extreme $\mathrm{M}-\mathrm{O}_{\text {water }}$ distance. Chemistry 9: 1394-1404, 2003.

14. Burai L, Scopelliti R and Tóth É: Eu ${ }^{\text {II }}$-cryptate with optimal water exchange and electronic relaxation: A synthon for potential $\mathrm{pO}_{2}$ responsive macromolecular MRI contrast agents. Chem Commun (Camb) 20: 2366-2367, 2002.

15. Gamage N DH, Mei YJ, Garcia J and Allen MJ: Oxidatively stable, aqueous europium(II) complexes through steric and electronic manipulation of cryptand coordination chemistry. Angew Chem Int Ed Engl 49: 8923-8925, 2010.

16. Garcia J, Kuda-Wedagedara AN and Allen MJ: Physical properties of $\mathrm{Eu}^{2+}$-containing cryptates as contrast agents for ultra-high field magnetic resonance imaging. Eur J Inorg Chem 2012: 2135-2140, 2012.

17. Wu Y, Zhou Y, Ouari O, et al: Polymeric PARACEST agents for enhancing MRI contrast sensitivity. J Am Chem Soc 130: 13854-13855, 2008.

18. Wu CM and Jin JY: Research progress of CEST agent in MR imaging. Guoji Yixue Fangshexue Zazhi 32: 475-477, 2009 (In Chinese).

19. Zhang S, Winter P, Wu K and Sherry AD: A novel europium(III)-based MRI contrast agent. J Am Chem Soc 123: 1517-1518, 2001.

20. Wu Y, Zhao P, Kiefer GE and Sherry AD: Multifunctional polymeric scaffolds for enhancement of PARACEST contrast sensitivity and performance: Effects of random copolymer variations. Macromolecules 43: 6616-6624, 2010. 